\title{
PLASMA-SYNTHESISED ZINC OXIDE NANOPARTICLE BEHAVIOR IN LIQUIDS
}

\author{
${ }^{1 *}$ David RUTHERFORD, ${ }^{1} J a r o s l a v ~ J I ́ R A, ~{ }^{2}$ Kateřina KOLÁŘOVÁ, ${ }^{3}$ Iva MATOLÍNOVÁ, \\ ${ }^{2}$ Zdenek REMEŠ, ${ }^{1}$ Jaroslav KULIČEK, ${ }^{4}$ Dilli PADMANABAN, ${ }^{4}$ Paul MAGUIRE, ${ }^{4}$ Davide MARIOTTI, \\ ${ }^{1}$ Bohuslav REZEK \\ ${ }^{1}$ Department of Physics, Czech Technical University, Prague, Czech Republic, EU, *ruthedav@fel.cvut.cz \\ ${ }^{2}$ Institute of Physics, Czech Academy of Sciences, Prague, Czech Republic, EU \\ ${ }^{3}$ Department of Surface and Plasma Science, Charles University, Prague, Czech Republic, EU \\ ${ }^{4}$ School of Engineering, Ulster University, Belfast, N. Ireland
}

https://doi.org/10.37904/nanocon.2021.4318

\begin{abstract}
Zinc oxide nanoparticles have been synthesized using non-thermal atmospheric pressure plasma (ZnO-NTP). We investigated the behavior of these ligand-free as a colloid suspension using different solvents, from deionized water to physiological saline and microbial culture broth. We found that the zeta potential of $\mathrm{ZnO}$ NTP became more negative after exposure to microbial culture broth relative to water, which suggests increased colloid stability. Photoluminescence spectra of ZnO-NTP were similar regardless of liquid type, yet optical and fluorescent images of samples showed different agglomeration behavior depending on liquid type. Scanning electron microscopy images revealed large agglomerates of ZnO-NTP interacting with the surface of bacteria cells, ranging in size from $200 \mathrm{~nm}$ up to $2 \mu \mathrm{m}$. We also studied effect of sub-lethal concentrations of ZnO-NTP on bacteria under illumination. There was no significant difference in viable bacteria concentration after $24 \mathrm{~h}$ exposure to $10 \mu \mathrm{g} / \mathrm{mL} \mathrm{ZnO}-\mathrm{NTP}$ relative to untreated control irrespective of sample illumination.
\end{abstract}

Keywords: Zinc oxide, nanotechnology, colloid suspension, bacteria

\section{INTRODUCTION}

Non-thermal plasma (NTP) have emerged as a promising technology for the synthesis of highly crystalline nanoparticles [1,2]. Commercially available nanoparticles produced on an industrial scale can result in the introduction of unwanted impurities that can negatively impact their integration into downstream applications. For example, according to the material safety data sheet for spherical zinc oxide nanoparticles (ZnO NP), there may be traces of aluminum oxide present [3]. NTP can be described as a green synthesis technique, in that no toxic chemicals are required in the generation of $\mathrm{ZnO}$ NP. There are a number of examples where NTP have been used to synthesize $\mathrm{ZnO} N \mathrm{NP}$ [4-7]. However, their interaction with complex liquids of biological relevance remains yet to be fully explored.

Nanoparticles are greatly influenced by their surrounding environment due to the high surface area to volume ratio making them highly responsive to the water chemistry of the solvent when in a colloidal suspension. Thus, their behavior in the colloid as well as inherent properties can be suppressed or enhanced by surface interaction with other molecules that are also present in the liquid such as proteins or carbohydrates. Our prior computer simulations showed that the interaction between amino acids and zinc oxide surface involved covalent bonding and not merely due to passive adsorption [8].

Here, we synthesize $\mathrm{ZnO}$ nanoparticles by using non-thermal atmospheric-pressure plasma (ZnO-NTP) and characterize its material properties under specific conditions. The nanoparticles are then introduced in liquids 
of varying ionic and biomolecule content and we measure the resulting optical and colloidal and microbiological effects.

\section{MATERIALS AND METHODS}

\subsection{Nanoparticle synthesis}

$\mathrm{ZnO}$ nanoparticles were synthesized using a non-thermal plasma reactor (Figure $\mathbf{1} \mathbf{A}$ ) consisting of a hollow stainless steel housing with a quartz tube ( $1 \mathrm{~mm}$ outer diameter, $0.7 \mathrm{~mm}$ inner diameter) and a pure zinc wire ( $0.5 \mathrm{~mm}, 99.99 \%$, Alfa Aesar) positioned inside the housing attached to ground. The wire along with the quartz tube was placed inside a copper plate which was connected to a radio-frequency $(40 \mathrm{~W}, 13.56 \mathrm{MHz})$ power source connected using a matching network. A mass flow controller delivered helium $(\mathrm{He}, 0.3 \mathrm{slm})$ into the housing and a gas-phase microplasma ignited within the quartz tube and interacted with the zinc wire. Generated nanoparticles (ZnO-NTP) were transported away from the microplasma by the gas flow and collected downstream on a clean Si (intrinsic) substrate at a rate of $0.3 \mathrm{mg} / \mathrm{s}$. The dry powder was then transferred to a clean vial and used for characterization analyses.

\subsection{Nanoparticle characterization}

The crystallographic profile of the synthesized ZnO-NTP was explored by high-resolution transmission electron microscope (TEM, Jeol JEM02100 F) coupled to selected area electron diffraction (SAED) to determine particle morphology, phase and size distribution after the synthesis. The transmission microscopy images and SAED patterns were analyzed using ImageJ (1.48v) software for particle size distribution and d-spacing calculation. ZnO-NTP optical properties were probed using UV-visible spectroscopy (UV-vis, PerkinElmer LAMDA 365), and photoluminescence ( $\mathrm{PL}, \mathrm{WITec}$, alpha300 RAS) after exposure to liquids: demineralized water $\left(\mathrm{dH}_{2} \mathrm{O}\right.$, Resta), $0.9 \%$ sodium chloride ( $\mathrm{NaCl}$, Penta) and Mueller Hinton broth (MHB, Oxoid). The size distribution and zeta potential of ZnO-NTP after exposure to different liquids was analyzed by dynamic light scattering (ZetaSizer, Malvern).

A stock solution of ZnO-NTP and dilutions thereof were made using demineralized $\mathrm{H}_{2} \mathrm{O}(<1 \mu \mathrm{S} / \mathrm{cm})$ and subjected to sonication prior to analysis ( $160 \mathrm{~W}$ for $30 \mathrm{~min}$, DT31, Sonorex Digitec). For PL and zeta potential measurements, $\mathrm{ZnO}$-NTP were first removed from $\mathrm{dH}_{2} \mathrm{O}$ by centrifugation (30min at $13 \mathrm{k} \mathrm{rpm}, \mathrm{MPW}-150 \mathrm{R}$ ) followed by resuspending in the same volume of a different liquid type. ZnO-NTP were subsequently vortexed in either $\mathrm{dH}_{2} \mathrm{O}, 0.9 \% \mathrm{NaCl}$ or $\mathrm{MHB}(8000 \mathrm{rpm}, 1 \mathrm{~min})$ before sonication under the same conditions previously used. The liquid was removed by centrifugation again and $\mathrm{ZnO}-\mathrm{NTP}$ were re-suspended in $\mathrm{dH}_{2} \mathrm{O}$ for a final round of sonication before analysis.

\subsection{Nanoparticle interaction with bacteria}

Escherichia coli (E. coli, CCM 3954, Brno) were resuscitated on Mueller Hinton agar (MHA, Carl Roth) plates and cultivated overnight $\left(37^{\circ} \mathrm{C}\right)$. The following day, 1 colony was removed and resuspended in $100 \mathrm{~mL} \mathrm{MHB}$ and placed on an orbital shaker located inside an incubator (150 rpm for $24 \mathrm{~h}$ at $37^{\circ} \mathrm{C}$ ). Next, the bacteria were adjusted to McFarland's Density 1.0 in fresh MHB using a densitometer (Biosan), then subsequently diluted 1:1000 in fresh MHB to an approximate concentration of $1 \times 10^{5} \mathrm{cfu} / \mathrm{mL}$. $1 \mathrm{~mL}$ of $\mathrm{ZnO}-\mathrm{NTP}$ in $\mathrm{dH}_{2} \mathrm{O}(100$ $\mu \mathrm{g} / \mathrm{mL}$ ) was added to $9 \mathrm{~mL} E$. coli in a $50 \mathrm{~mL}$ Falcon tube and placed inside reverse spin bioreactors (2000 $\mathrm{rpm} / 1 \mathrm{~s}$, RTS-1, BioSan) with and without illumination (Reflekta). The white light source was selected based on overlapping spectral output and UV-vis absorbance profile of ZnO-NTP (i.e. between $400-500 \mathrm{~nm}$ ). The concentration of viable bacteria was measured at the start and again after 24 hours by performing a 1:10 dilution series using $0.9 \% \mathrm{NaCl}$ and inoculating onto MHA before incubating ( $37^{\circ} \mathrm{C}$ for $\left.24 \mathrm{~h}\right) .100 \mu \mathrm{L}$ of the bacteria-ZnO-NTP mixture was removed after $24 \mathrm{~h}$ and diluted 1:100 in $\mathrm{dH}_{2} \mathrm{O}$ then $10 \mu \mathrm{L}$ was drop-casted 
onto silicon wafer for SEM analysis (MIRA III, Tescan). It was not possible to image ZnO-NTP in $0.9 \% \mathrm{NaCl}$ or MHB using SEM due considerable crystallization of salts and other components on the substrate.

\section{RESULTS}

\subsection{Morphology, UV-vis and phase}

Morphology of the synthesized ZnO-NTP collected in ethanol was probed using TEM and the images showed uniform grain-like shaped particles (Figure 1 (B)). One can see that the particles are well dispersed with individual primary particles clearly visible. Analysis of TEM images revealed the mean particle size was 18.6 $\pm 6.5 \mathrm{~nm}$ and there was a log normal distribution with regards to particle diameter and number (Figure 1 (C)). Figure 1 (D) shows a Tauc plot derived from UV-vis absorbance data of ZnO-NTP in ethanol and the energy band gap (Eg) calculated to be approximately $3.22 \mathrm{eV}$. Figure 1 (E) shows the SAED profile of ZnO-NTP that displays a hexagonal wurzite phase (space group $\mathrm{P}_{63} \mathrm{mc}$, indexed based on JCPDF file \# 65-3411).
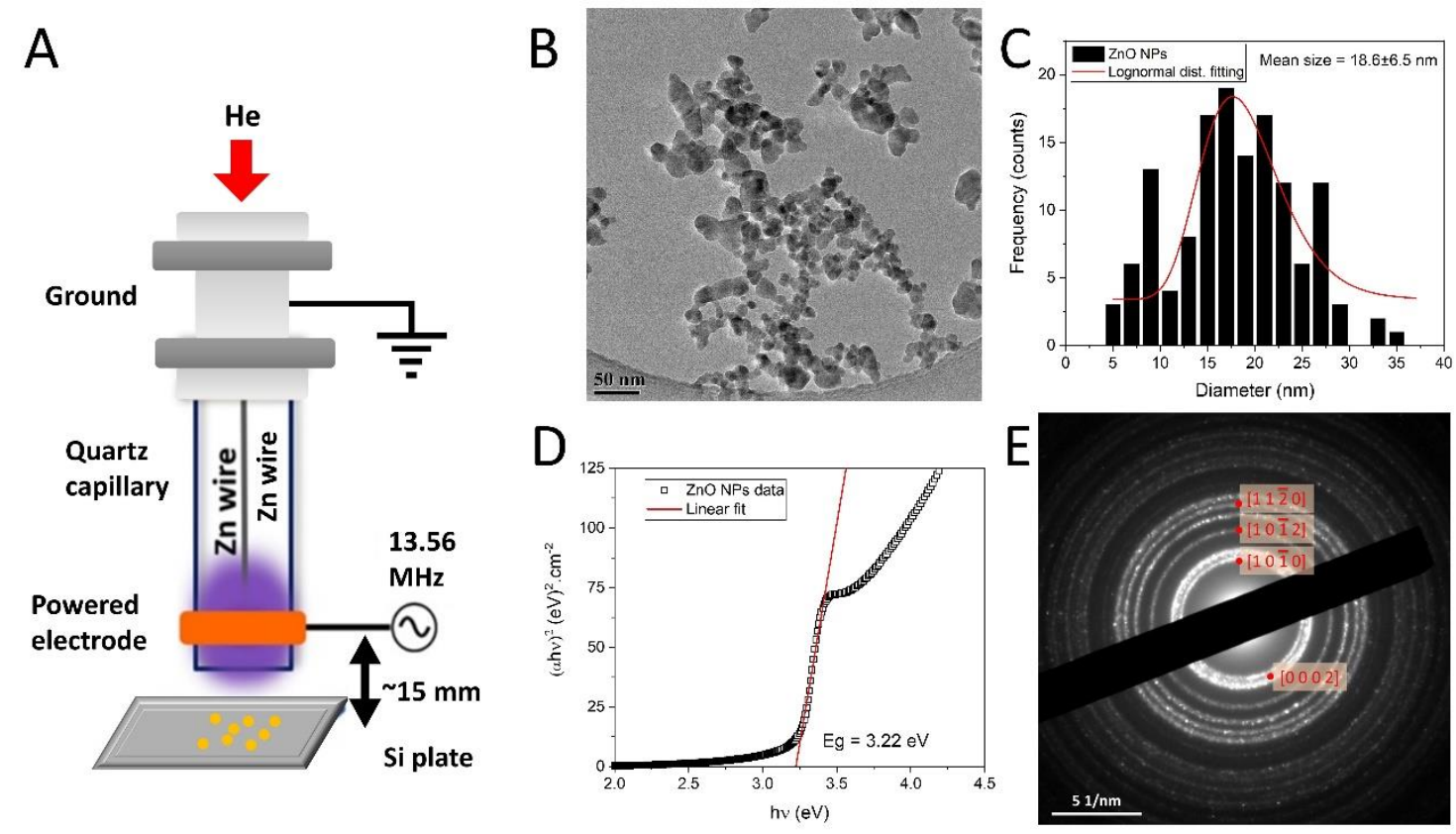

Figure 1 (A) Schematic diagram of the non-thermal atmospheric pressure plasma system with zinc wire used for $\mathrm{ZnO}$ nanoparticle synthesis (ZnO-NTP). (B) TEM image of ZnO-NTP. (C) Histogram showing size distribution analysis from TEM images. (D) Tauc plot derived from ZnO-NTP absorbance data obtained using UV-vis spectroscopy (E) SAED profile of ZnO-NTP.

\subsection{Zeta potential and DLS}

ZnO-NTP were first exposed to $\mathrm{dH}_{2} \mathrm{O}$ and then suspended in 3 liquid types during sonication before being resuspended in $\mathrm{dH}_{2} \mathrm{O}$ for size distribution and zeta potential analysis. From Figure 2, one can see three main size fractions from in MHB-exposed ZnO-NTP, specifically at $79 \mathrm{~nm}, 712 \mathrm{~nm}$, and $5560 \mathrm{~nm}$. This correlates well with the zeta potential measurements, where there were also three peaks detected, at $-36.6 \mathrm{mV},-23.4$ $\mathrm{mV}$ and $-7 \mathrm{mV}$. There were also three distinct size fractions observed from $\mathrm{dH}_{2} \mathrm{O}$-exposed $\mathrm{ZnO}-\mathrm{NTP}$, at 396 $\mathrm{nm}, 1484 \mathrm{~nm}$ and $4801 \mathrm{~nm}$. However, the different sized particles generated a single peak for zeta potential measurement at $-12.4 \pm 0.4 \mathrm{mV}$. ZnO-NTP exposed to $0.9 \% \mathrm{NaCl}$ became more positive with an observed value of $5.3 \pm 0.6 \mathrm{mV}$, however DLS analysis was unable to detect particles below $10 \mu \mathrm{m}$ even after extensive sonication prior to measurement which makes the value unreliable. 

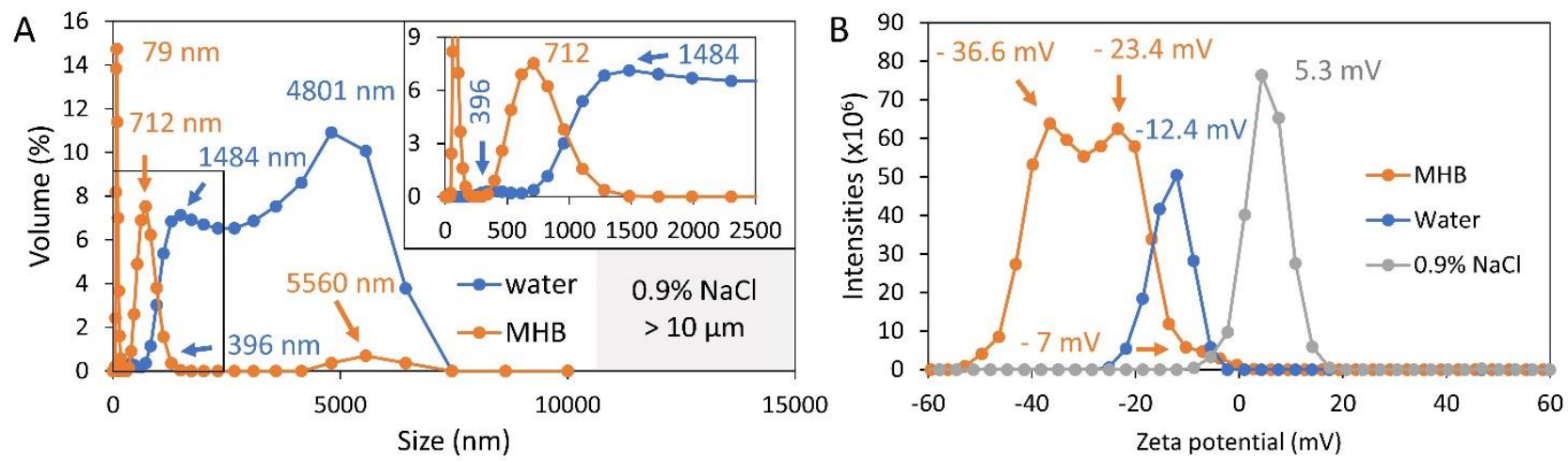

Figure 2 ZnO-NTP size distribution according to volume (A) and intensities with corresponding zeta potential (B). Numbers inset indicate measured values and arrows point to the specific data

\subsection{Photoluminescence (PL)}

Room temperature PL spectra from ZnO-NTP dried under ambient conditions on Si wafer and illuminated using blue laser (430-435 nm) and filter can be seen in Figure 3 (A). The line profile of each PL spectra is similar regardless of liquid type, with a dominant peak between 600-610 nm and two troughs located either side at $590 \mathrm{~nm}$ and $615 \mathrm{~nm}$. No new peaks were detected from any ZnO-NTP and the maximum PL intensity was recorded at the same wavelength in each sample $(606 \mathrm{~nm})$.

A

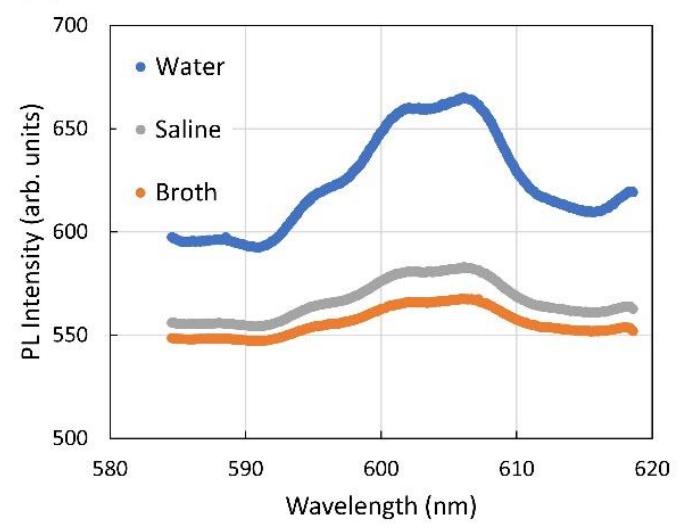

$\mathrm{dH}_{2} \mathrm{O}$
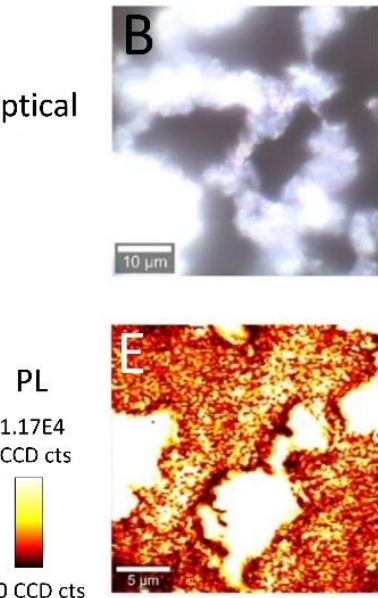

MHB
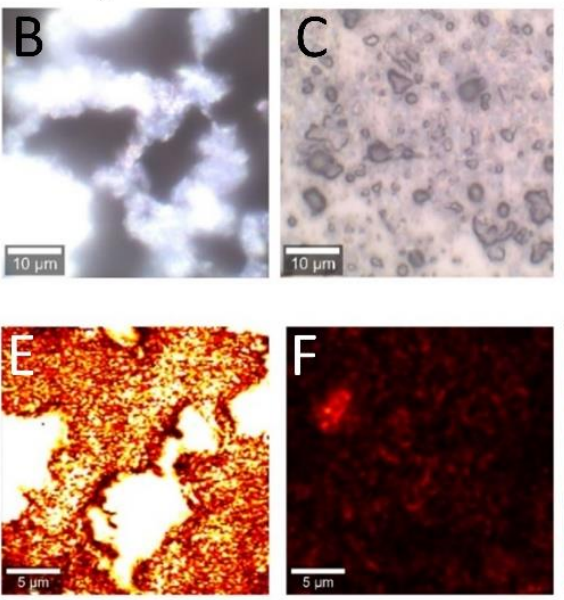

Optical

0 CCD cts

\section{$0.9 \% \mathrm{NaCl}$}
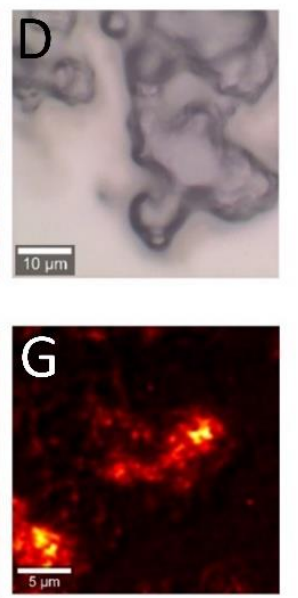

Figure $3 \mathrm{PL}$ spectra of ZnO-NTP illuminated by blue light (430-435 nm) using $570 \mathrm{~nm}$ filter (A). Optical (B-D) and fluorescent $(E-G)$ images of ZnO-NTP that generated the spectra in A

Optical image of $\mathrm{ZnO}-\mathrm{NTP}$ exposed to $\mathrm{dH}_{2} \mathrm{O}$ showed large agglomerates (Figure $3(\mathrm{~B})$ ) with strong fluorescent emission (Figure $3(E)$ ). ZnO-NTP exposed to $0.9 \% \mathrm{NaCl}$ also showed agglomeration (Figure 3 (D)), but without the strong fluorescent emission seen previously for $\mathrm{dH}_{2} \mathrm{O}$-exposed $\mathrm{ZnO}-\mathrm{NTP}$ (Figure $3(\mathbf{G})$ ). The optical image of MHB-exposed ZnO-NTP showed the most dispersed arrangement of particles (Figure 3 (C) with the least amount of fluorescence (Figure $3(\mathbf{F})$ ).

\subsection{Interaction with bacteria (cfu/mL \& SEM)}

Reverse spin bioreactors enabled interaction between a low concentration of ZnO-NTP $(10 \mu \mathrm{g} / \mathrm{mL})$ and E. coli in MHB. From our previous work, $10 \mu \mathrm{g} / \mathrm{mL} \mathrm{ZnO}$ did not inhibit growth of $E$. coli in MHB. Here, we employed yet another different type of $\mathrm{ZnO}$ nanoparticles (in shape and size) and studied also the effect of illumination 
with a non-bactericidal white light source having spectral output overlapping with UV-vis absorbance profile of ZnO-NTP (i.e. between 400-500 nm).

There was no significant difference in $E$. coli concentration after $24 \mathrm{~h}$ exposure to ZnO-NTP relative to unexposed (control) regardless of illumination (P>0.05, Figure 4 (A). SEM image of E. coli-ZnO-NTP taken after $24 \mathrm{~h}$ exposure revealed small particles resting on the cell surface, as well porous superstructures that were large enough to interact with whole bacteria cells (Figure 4 (B)).
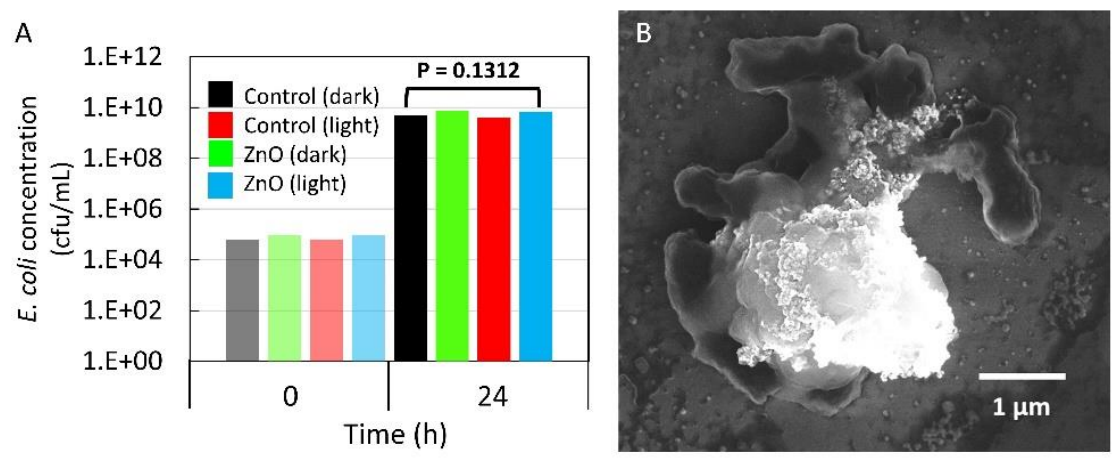

Figure 4 (A) Bar chart displaying the concentration of viable E. coli at the start of the experiment $(0)$ and after $24 \mathrm{~h}$ exposure to $10 \mu \mathrm{g} / \mathrm{mL}$ ZnO-NTP in reverse spin bioreactors. (B) Scanning electron microscopy image showing a size range of ZnO-NTP aggregates interacting with multiple E. coli cells.

\section{DISCUSSION}

Novel non-thermal plasma technique has been demonstrated to synthesize $\mathrm{ZnO}$ nanoparticles of specifically small size, shape and quality at room temperature without any harsh chemicals or large vacuum systems. The non-equilibrium nature inside the discharge region causes reactions occur rapidly and continue in the afterglow where atmospheric gases and humidity gain influence that can lead to the formation of reactive oxygen and nitrogen species (RONS). Nanoparticle formation arises from plasma interaction with nanoparticle precursor atom/molecule in either the feed gas mixture, liquid solution, or solid substrate. Here, a solid zinc wire was placed inside an rf-driven non-thermal plasma using $\mathrm{He}$ as the feed gas which carried ZnO-NTP away from the core plasma region for collection. TEM image of ZnO-NTP showed uniform grain morphology with a log normal size distribution and mean particle diameter of $19 \mathrm{~nm}$, however there were also many particles at around $10 \mathrm{~nm}$ and $30 \mathrm{~nm}$. The same plasma system was also capable of synthesizing smaller ZnO quantum dots with a mean particle diameter of $1.9 \mathrm{~nm}$ when operating under the same power conditions but using argon instead of helium [7]. This suggests that it is possible to control the size of the nanoparticle synthesized using non-thermal plasma by varying the feed gas composition.

ZnO-NTP showed typical UV light absorbance behavior, with a sharp peak at the maximum absorbance wavelength of $370 \mathrm{~nm}$ and the calculated energy band gap from Tauc plot derived from absorbance data was $3.22 \mathrm{eV}$, which is in good agreement with the literature [9]. ZnO-NTP also exhibited photoluminescence when illuminated with light of smaller energy than the band gap $(\lambda=430-435 \mathrm{~nm})$. The PL spectra are similar, and the maximum PL intensity remained at $606 \mathrm{~nm}$ in all samples irrespective of liquid type. Thus, the PL spectra are robust in biological environment. Such PL emission arises due to $\mathrm{ZnO}$ surface defects $[9,10]$.

The observed differences in PL intensities between ZnO-NTP exposed to different liquid types are most likely due to variation in sample thickness which is influenced in part by material agglomeration as shown in the optical images in Figure 3. The PL microscopic images showed high particle agglomeration in water, which could account for the higher PL signal compared to $0.9 \% \mathrm{NaCl}$ and MHB. Nevertheless, prior reports showed that the PL emission can be quenched by amino acid residues from proteins bound to the surface of $\mathrm{ZnO}$ [11]. Quenching of the fluorescence of BSA due to interaction with ZnO NP through the formation of stable ground 
state complexes was also observed [12], highlighting the fact that both ZnO NP and BSA can influence each other's properties and it is not solely the action of one or the other. Such complex interaction could be occurring in our case, where biomolecules contained in MHB may coat ZnO-NTP, forming a protein/carbohydrate corona that results in PL emission quenching.

Protein coronas also tend to increase particle aggregation due to enhanced particle-particle interaction thereby creating a less well dispersed population. Yet the PL images showed that MHB-exposed ZnO-NTP to be the most dispersed material compared to $\mathrm{dH}_{2} \mathrm{O}$ and $0.9 \% \mathrm{NaCl}$-exposed $\mathrm{ZnO}-\mathrm{NTP}$.

Zeta potential analysis of MHB-exposed ZnO-NTP also implied a more dispersed population compared to $\mathrm{dH}_{2} \mathrm{O}$ and $0.9 \% \mathrm{NaCl}$-exposed ZnO-NTP. There were three distinct peaks in both zeta potential measurement and size distribution for MHB-exposed ZnO-NTP, two pronounced peaks and one much smaller. The values of the two pronounced peaks $(-36.6 \mathrm{mV}$ and $-23.4 \mathrm{mV})$ were more negative than the single peak from $\mathrm{dH}_{2} \mathrm{O}$ exposed ZnO-NTP of $-12.4 \mathrm{mV}$. A higher absolute value of zeta potential can result in a more disperse population of particles in the suspension due to better electrostatic repulsion of nanoparticles. Zeta potential of $\mathrm{ZnO}$ also became more negative after exposure to biomolecules such as BSA [13], in agreement with our data in MHB. The third peak from zeta potential measurement was less negative than the prior two $(-7 \mathrm{mV})$ which may have been generated from the larger size fraction at $5560 \mathrm{~nm}$ which accounted for a small percentage of the total volume of particles. For MHB-exposed ZnO-NTP, one can assume that the three separate peaks observed in zeta potential analysis were generated from the three different size fractions. However, this was not the case for $\mathrm{dH}_{2} \mathrm{O}$-exposed $\mathrm{ZnO}$-NTP where there were three size fractions observed yet only one zeta potential peak. This suggests that the effect of $\mathrm{MHB}$ on the size and zeta potential of $\mathrm{ZnO}$ NTP is more pronounced than for $\mathrm{dH}_{2} \mathrm{O}$. The two smaller size fractions from MHB-exposed $\mathrm{ZnO}-\mathrm{NTP}(79 \mathrm{~nm}$ and $712 \mathrm{~nm}$ ) were smaller than the two smallest size fractions from $\mathrm{dH}_{2} \mathrm{O}$-exposed $\mathrm{ZnO}-\mathrm{NTP}$ (396 $\mathrm{nm}$ and $1484 \mathrm{~nm}$ ) which also suggests a more dispersed population of particles with smaller aggregates. However, even the smallest size fraction observed $(79 \mathrm{~nm})$ was larger than the primary particle size seen from TEM image in Figure $1(19 \mathrm{~nm})$, therefore some aggregation of primary particles occurs on MHB-exposed ZnONTP. Upon exposure to $0.9 \% \mathrm{NaCl}$, the zeta potential of ZnO-NTP shifted to a less negative value of $5.3 \mathrm{mV}$. This trend was also observed for $\mathrm{ZnO} N P$ exposed to increasing $\mathrm{NaCl}$ concentrations, from $-28 \mathrm{mV}$ to $-2 \mathrm{mV}$, however the highest concentration of $\mathrm{NaCl}$ used in that study and produced the least negative zeta potential was $\times 30$ less than what was used in our experiments [14].

It has been reported in the literature that the smaller the nanoparticle, the greater the antibacterial effect [15]. This is also true for aggregates of particles and one might expect greater antibacterial effect from more dispersed colloidal suspension. However, we have previously shown that particle morphology is also important in the antibacterial effect of $\mathrm{ZnO}$ in $\mathrm{MHB}$, and particles with uniform rounded morphology were less antibacterial than particles composed of many needle-like clusters [16]. At the same concentration used here $(10 \mu \mathrm{g} / \mathrm{mL})$, there was no significant difference in viable bacteria relative to unexposed bacteria regardless of $\mathrm{ZnO}$ size or shape. At higher concentrations ( $\geq 100 \mu \mathrm{g} / \mathrm{mL}$ ), the needles were still sufficiently sharp even after being coated with components of MHB to inactivate bacteria by puncturing the cell membrane, whereas the more rounded particles tended to aggregate on the cell surface. A non-bactericidal white light source with overlapping spectral output and UV-vis absorbance profile of ZnO-NTP was chosen to try and enhance the antibacterial effect (i.e. between $400-500 \mathrm{~nm}$ ). Visible light photoinactivation of bacteria mediated by $\mathrm{ZnO}$ has been reported that was mainly attributed to the bactericidal effect of zinc ions [17]. We have previously shown that without illumination the concentration of zinc ion produced in MHB would not be great enough to become cytotoxic due to the components in MHB scavenging zinc ion before interacting with bacteria [16]. However, hydrogen peroxide was measured from illuminating a much higher concentration of commercially available $\mathrm{ZnO}(2 \mathrm{mg} / \mathrm{mL})$ using the same experimental set up and illumination source used here (unpublished data). 


\section{CONCLUSION}

Variation in the physicochemical properties of ZnO-NTP nanoparticles due to the effect of exposure to various liquids was observed. Interestingly, the best dispersion was observed in cell culture MHB medium, providing smallest aggregates $(79 \mathrm{~nm})$ and most negative zeta potential $(-36.6 \mathrm{mV})$. The PL spectra remained unaffected. In the employed sub-lethal concentration the ZnO-NTP nanoparticles rather enhanced the bacterial growth, as observed for other ZnO NP types before. Yet illumination did not lead to any bactericidal effect, unlike for other $\mathrm{ZnO}$ nanoparticle types. This must be related with specific nanoparticle preparation using nonthermal plasma. This means that photoexcitation and PL spectra can be used as a robust sensing pathway in biological environment.

\section{ACKNOWLEDGEMENTS}

The presented work was supported financially by the project GACR 19-02858J.

\section{REFERENCES}

[1] KORTSHAGEN, U. R., SANKARAN, R. M., PEREIRA, R. N., GIRSHICK, S. L., WU, J. J. and AYDIL, E. S. Nonthermal Plasma Synthesis of Nanocrystals: Fundamental Principles, Materials, and Applications Chem. Rev. 2016, vol. 116, pp. 11061-127.

[2] CHIANG, W-H, MARIOTTI, D., SANKARAN, R. M., EDEN, J. G. and OSTRIKOV, K. (Ken) Microplasmas for Advanced Materials and Devices Advanced Materials 2020, vol. 32, 1905508.

[3] Anon 2019 Material Safety Data Sheet (MSDS) - ZnO

[4] FELBIER, P., YANG, J., THEIS, J., LIPTAK, R. W., WAGNER, A., LORKE, A., BACHER, G. and KORTSHAGEN, U. Highly Luminescent ZnO Quantum Dots Made in a Nonthermal Plasma Advanced Functional Materials. 2014, vol. 24, pp. 1988-93

[5] TSUMAKI, M., SHIMIZU, Y. and ITO, T. Size-controlled sub-micrometer spheroidized ZnO particles synthesis via plasma-induced processing in microdroplets Materials Letters. 2016, vol. 166, pp. 81-4.

[6] JAIN, G., MACIAS-MONTERO, M., VELUSAMY, T., MAGUIRE, P. and MARIOTTI, D. Porous zinc oxide nanocrystalline film deposition by atmospheric pressure plasma: Fabrication and energy band estimation. Plasma Process Polym. 2017, vol. 14, 1700052.

[7] JAIN, G., ROCKS, C., MAGUIRE, P. and MARIOTTI, D. One-step synthesis of strongly confined, defect-free and hydroxy-terminated ZnO quantum dots Nanotechnology 2020, vol. 31, 215707.

[8] REZEK, B., HEMATIAN, H., JÍRA, J., RUTHERFORD, D., KULIČEK, J., UKRAINTSEV, E. and REMEŠ, Z. Microscopic Study of Bovine Serum Albumin Adsorption on Zinc Oxide (0001) Surface physica status solidi (a) 2021, vol. 218, 2000558.

[9] ISLAM, S. and AKYILDIZ, H. I. Immobilization of $\mathrm{ZnO}$ thin films onto fibrous glass substrates via atomic layer deposition and investigation of photocatalytic activity J Mater Sci: Mater Electron. 2021, vol. 32, pp. 27027-43.

[10] DJURIŠIĆ, A. B., LEUNG, Y. H., TAM, K. H., HSU, Y. F., DING, L., GE, W. K., ZHONG, Y. C., WONG, K. S., CHAN, W. K., TAM, H. L., CHEAH, K. W., KWOK, W. M. and PHILLIPS, D. L. Defect emissions in ZnO nanostructures. Nanotechnology. 2007, vol. 18, 095702.

[11] BHUNIA, A. K., KAMILYA, T. and SAHA, S. Temperature Dependent and Kinetic Study of the Adsorption of Bovine Serum Albumin to ZnO Nanoparticle Surfaces ChemistrySelect. 2016, vol. 1, pp. 2872-82.

[12] HANSDA, C., MAITI, P., SINGHA, T., PAL, M., HUSSAIN, S. A., PAUL, S. and PAUL, P. K. Photophysical study of the interaction between $\mathrm{ZnO}$ nanoparticles and globular protein bovine serum albumin in solution and in a layer-by-layer self-assembled film Journal of Physics and Chemistry of Solids 2018, vol. 121, pp. 110-20.

[13] BHUNIA, A. K., KAMILYA, T. and SAHA, S. Synthesis, Characterization of ZnO Nanorods and its Interaction with Albumin Protein Materials Today: Proceedings. 2016, vol. 3, pp. 592-7.

[14] PENG, Y.-H., TSO, C., TSAI, Y., ZHUANG, C. and SHIH, Y. The effect of electrolytes on the aggregation kinetics of three different ZnO nanoparticles in water Science of The Total Environment. 2015, vol. 530-531, pp. $183-90$. 
[15] KAUSHIK, M., NIRANJAN, R., THANGAM, R., MADHAN, B., PANDIYARASAN, V., RAMACHANDRAN, C., OH, D-H. and VENKATASUBBU, G. D. Investigations on the antimicrobial activity and wound healing potential of $\mathrm{ZnO}$ nanoparticles Applied Surface Science 2019, vol. 479, pp. 1169-77.

[16] RUTHERFORD, D., JíRA, J., KOLÁŘOVÁ, K., MATOLíNOVÁ, I., MIČOVÁ, J., REMEŠ, Z. and REZEK, B. Growth Inhibition of Gram-Positive and Gram-Negative Bacteria by Zinc Oxide Hedgehog Particles. IJN. 2021, vol. 16, pp. 3541-54.

[17] SAPKOTA, A., ANCENO, A. J., BARUAH, S., SHIPIN, O. V. and DUTTA, J. Zinc oxide nanorod mediated visible light photoinactivation of model microbes in water Nanotechnology 2011, vol. 22, 215703. 